\title{
Reasons for the Extremely Small Population of putative hybrid Sonneratia $\times$ hainanensis W.C. Ko (Lythraceae)
}

\author{
Mengwen Zhang ${ }^{1}$, Xiaobo Yang ${ }^{2, *}$, Wenxing Long ${ }^{3}$, Donghai $\mathrm{Li}^{2}$ and Xiaobo $\mathrm{Lv}^{1}$ (1) \\ 1 College of Life and Pharmaceutical Sciences, Hainan University, Haikou 570228, China; \\ zaizai_qq@163.com (M.Z.); lvxbo1980@sina.cn (X.L.) \\ 2 College of Ecology and Environment, Hainan University, Haikou 570228, China; dhlye@163.com \\ 3 College of Forestry, Hainan University, Haikou 570228, China; oklong@hainanu.edu.cn \\ * Correspondence: yanfengxb@hainu.edu.cn
}

Received: 13 April 2019; Accepted: 22 June 2019; Published: 25 June 2019

\begin{abstract}
Sonneratia $\times$ hainanensis, a species once endemic to Hainan Island in China, is now endangered. China's State Forestry Administration lists this species as a wild plant species with an extremely small population. Field fixed-point investigations, artificial pollination, and laboratory experiments, as well as other methods, were applied to study the reproductive system and seed germination of $S . \times$ hainanensis to elucidate the reasons for the endangerment of this species. The results are as follows: (1) Outcrossing index, pollen-ovule ratio, and artificial pollination showed $S . \times$ hainanensis has a mixed mating system and mainly focuses on outcrossing with some self-compatibility. (2) Fruit and seed placement tests showed that the fruit predators on the ground were mainly Fiddler crab and squirrel, with the predation rates being $100 \%$. The artificially spread seeds do not germinate under natural conditions. The mean seed destruction rate and remaining rate of were $82.5 \%$ and $17.5 \%$. (3) Seeds need to germinate under ambient light conditions, with an optimal photoperiod of $12 \mathrm{~h}$. Seed germination is extremely sensitive to low temperatures because of optimum temperatures from $30^{\circ} \mathrm{C}$ to $40^{\circ} \mathrm{C}$. At an optimal temperature of $35^{\circ} \mathrm{C}$, the seeds germinate under salinities ranging from $0 \%$ o to $7.5 \%$, with an optimal salinity of $2.5 \%$, which shows the sensitivity of seed germination to salinity, with low salinity promoting germination, whereas high salinity inhibits germination. These findings indicate that the limited regeneration of $S . \times$ hainanensis is caused by the following: (1) Pollen limitation and inbreeding recession caused by the extremely small population of $S . \times$ hainanensis. (2) Seeds near parent trees are susceptible not only to high fruit drop rate, but to high predation beneath the parent trees' canopy as well. (3) Seed germination has weak adaptability to light, temperature, and salinity.
\end{abstract}

Keywords: endangered; Sonneratia $\times$ hainanensis; reproductive system; seed germination; light; temperature; salinity

\section{Introduction}

Research on reproductive characteristics and reproductive dynamics effectively identifies the course that endangers the plant population and the underlying mechanism [1]. Moreover, it clarifies the reproductive biological characteristics and the effects of external factors on the most critical aspect of plant reproduction, as well as the mechanism that endangers plant species [2].

At the stage of pollination, research on the reproductive system of plants is helpful for understanding their life history and causes of endangerment [3]. Recent studies have shown that corolla shape, diameter, color, odor, and other factors affect pollinator variety, visiting frequency, 
and visual and olfactory reactions, which reduces the possibility of hybridization and adaptability of future generations. This effect leads to a decline in the number of species [4,5]. Pollen viability and stigma receptivity differ among plant species [6]. Highly dynamic pollen and stigma are conducive to pollination [7]. Conversely, presentation of pollen viability and stigma receptivity at different times influences pollination efficiency and limits the fruiting rate [8]. Moreover, the decline in pollination quality also causes various negative effects, including reproductive failure because of pollen restrictions, decline in genetic diversity, and depression from inbreeding [9]. Studies on plant species based on different population sizes and genetic variation demonstrate that inbreeding significantly affects seed rate, seed germination, survival, and resistance to stress [10].

Seeds are an important part of the life history of endangered plants [11]. Ecological research on the seeds of endangered plants reveals better approaches to breeding seeds and seedlings, which are of great significance for population expansion and preventing population extinction [12]. Some endangered plants have less natural production and low seed quality. This phenomenon fundamentally reduces the seed germination rate and restricts population growth [13]. Other endangered plants have special fruit morphologies or structures that are not conducive to the spread of seeds or germination, which also endangers these plants [14]. The seeds of some endangered plants have distinctive features, such as congenital dormancy or substances that inhibit germination, which leads to low sprouting rates and the scarcity of seedlings under natural forests [15]. Climate change and inefficient population regeneration in modern habitats can also be attributed to the limited expansion of endangered seeds and seedlings [16]. Some studies on Phoebe bournei (Hemsley) Yen C. Yang J.W. and Abies chensiensis Tieghem showed that animal damage to seeds and seedlings contribute to their scarcity in natural populations [17]. Moreover, the short life of seeds of endangered plants, such as Cinnamomum micranthum (Hay.) Hay and Cathaya argyrophylla Chun \& Kuang, also restricts their expansion [18].

Sonneratia $\times$ hainanensis W.C. Ko, E.Y. Chen and W.Y. Chen is an aiphyllium from the genus Sonneratia (Sonneratiaceae) [19]. This species grows on beaches near the low water line or on low tide beaches along inland rivers with low tidewater salinity [20]. The adult tree of Sonneratia $\times$ hainanensis is only eight and they are currently only found at Dongge and Touyuan in the Qinglan protection zone in Wenchang City, Hainan Province [21]. China's State Forestry Administration lists this species as a wild plant species with an extremely small population [22]. Studies on $S . \times$ hainanensis show that it has an outcross reproductive system with a long flowering phase [23]. It has flowers that can bloom almost year-round, although some Sonneratia species have overlapping flowering phases [24]. The outcross reproductive system, interspecific crossing sympatry, and overlapping flowering phases of Sonneratia provide chances for interspecific hybridization [25]. Among these species, $S$. $\times$ hainanensis is a diploid (22 chromosomes) hybrid, possibly between Sonneratia alba Smith and Sonneratia ovata Backer [26]. The $S . \times$ hainanensis population has a low genetic diversity, but various groups have significant genetic differentiation [27]. This phenomenon is possibly closely related to its reproductive system. However, few studies have investigated the reasons for restricted $S . \times$ hainanensis population in terms of the effects of reproductive ecology and environment on seed germination.

We conducted field fixed-point observations and laboratory experiments to study the reproductive system and seed germination of $S . \times$ hainanensis, as well as their relationship with the environment to determine the reasons for its limited natural regeneration.

\section{Materials and Methods}

\subsection{An Overview of the Sample Plot}

The sample plot was located at Qinglangang Nature Reserve of Hainan Island. Sonneratia plant communities in the region grow on the beach near the low water line or low tide beach along the inland river with low tidewater salinity. The area is located at $19^{\circ} 37^{\prime} 36^{\prime \prime} \mathrm{N}$ and $110^{\circ} 49^{\prime} 53^{\prime \prime} \mathrm{E}$. Mangrove plants present abundant varieties in these communities, including 24 species of true mangroves and 20 species of semi-mangroves. Sonneratia caseolaris (Linn.) Engler and Bruguiera sexangula (Loureiro) Poiret are 
the dominant mangrove species. In China, Sonneratia includes six species, namely, S. caseolaris, S. alba, Sonneratia apetala Buchanan-Hamilton, S. ovata, Sonneratia $\times$ gulngai N. C. Duke \& B.R. Jackes, and S. $\times$ hainanensis. S. apetala is an introduced exotic plant with a developed population, whereas, $S . \times$ hainanensis is a seriously endangered plant species. The geographical location is shown in Figure 1.

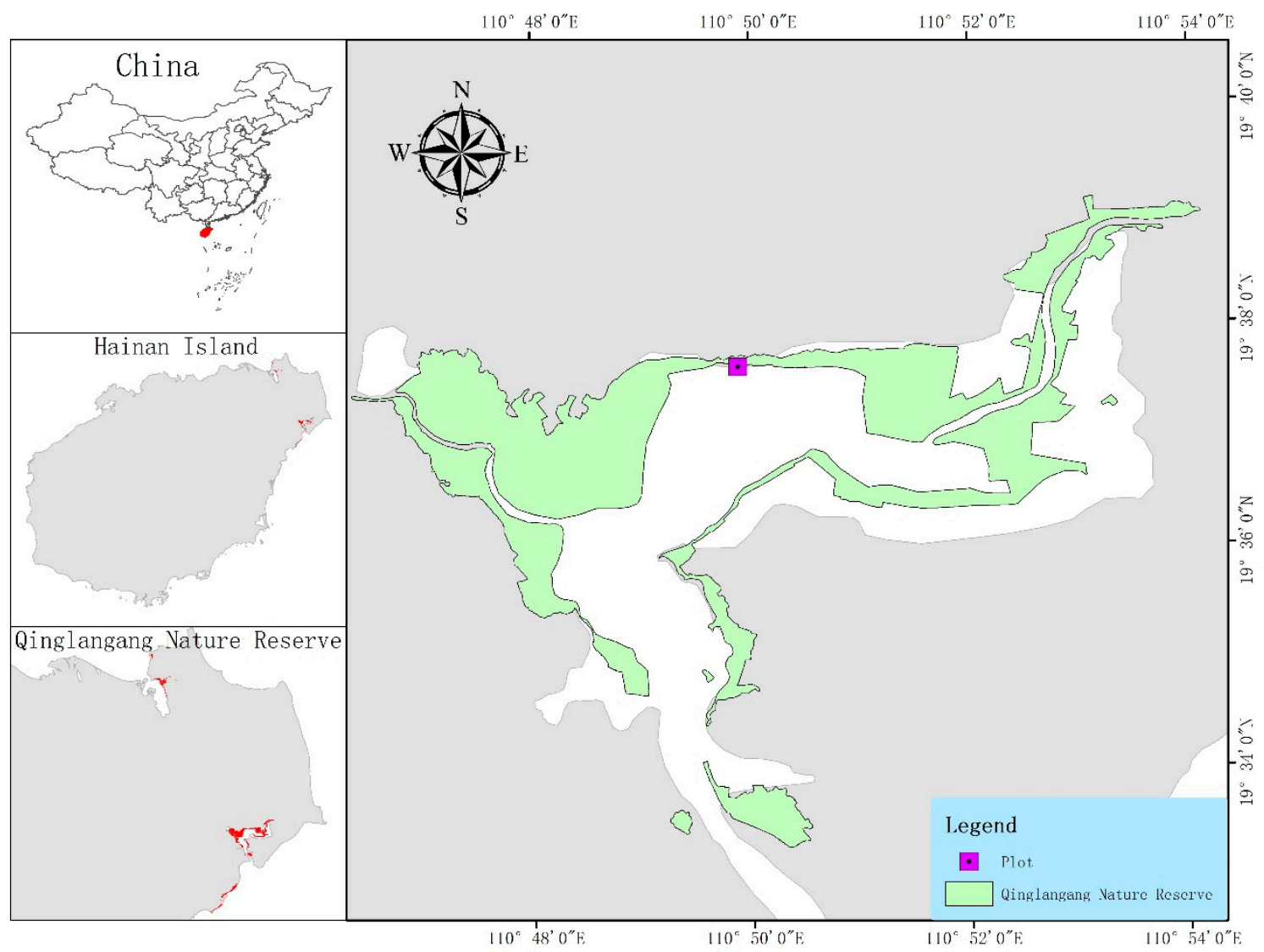

Figure 1. Geographic distribution of the fixed plot.

\subsection{Study Object}

We selected 8 trees of different $S . \times$ hainanensis strains from the bottomland of an enclosed sea harbor in Paigang Village, Dongge Town, Wenchang City, Hainan Province for the study. All trees were at least 100 years old, with strong trunks and branches. They were about $8 \mathrm{~m}$ high, with a diameter at breast height of $100 \mathrm{~cm}$, and a crown breadth of $15 \mathrm{~m} \times 15 \mathrm{~m}$. The fruit type of $S . \times$ hainanensis was spherical berry with a diameter of $50-80 \mathrm{~mm}$. The seeds were sickle-shaped, V-shaped, or irregular, with an average length of $10 \mathrm{~mm}$ and the outer seed coat was brown. There were 2 cotyledons, elliptical or oblong, $2-3 \mathrm{~cm}$ long, and $1-3 \mathrm{~cm}$ wide.

\subsection{Determination of the Reproductive System}

\subsubsection{Estimating the Outcrossing Index (OCI)}

Inflorescence diameter, flower size, and flowering behavior were measured and the assay of the reproductive system was specifically conducted according to the standards proposed by Dafni [28].

\subsubsection{Pollen to Ovule $(\mathrm{P} / \mathrm{O})$ ratio}

Ten buds just coming into bloom with undehisced anthers were randomly selected and fixed in formalin-acetic acid-alcohol (FAA). The number of single pollen grains was counted according to the method by Cruden, and the number of ovules was measured by paraffin section. The pollen to ovule 
$(\mathrm{P} / \mathrm{O})$ ratio of each flower was calculated by dividing the number of pollen grains by the number of ovules [29].

\subsection{Determination of the Reproductive System}

\subsubsection{Changes in Stigma Receptivity and Pollen Vitality with Time}

A total of 50 flowers were selected at the start and end of the period of high stigma receptivity. All stamens were carefully removed using tweezers before the blooming and isolated in a bag to prevent self-pollination. Fresh pollen grains were collected from other flowers. Flowers within 1 day to 5 days after pollination were isolated in a bag. Ten replicates were carried out during each flowering period.

A total of 50 flowers were selected at the start and end periods of pollen vitality. All stamens were carefully removed using tweezers before blooming. At the flowering day, the stigmas were pollinated with pollen from other flowers on the day of anther dehiscence and at 1 day to 5 days after dehiscence. Then, the stigmas were subjected to bag isolation. Ten repetitions were carried out for each pollen sample. Pollen germination rate and stigma receptivity were calculated according to the fruit setting rate during the preliminary stage. An ANOVA was used to compare the differences between pollen germination rate and stigma receptivity at different periods.

\subsubsection{Artificial Pollination and Bagging Experiments}

During the bud stage, one strain and 280 buds of $S . \times$ hainanensis were selected for seven pollination treatments: A, natural control (natural hybrid); B, bagging with castration without pollination (apomixia); C, net isolation with castration (anemophily pollination); D, no bagging; E, no bagging with castration (bagging before flowering and pollen from the same flower was given after flowering); F, artificial geitonogamy (mutual pollination of No. 1 and No. 10, No. 2 and No. 9, and so on for 10 buds); and G, artificial xenogamy (pollen source was from another strain of $S$. $\times$ hainanensis $100 \mathrm{~m}$ away from the experiment strain). The E, F, and $\mathrm{G}$ treatments involved artificial pollination, whereas A, B, C, and D were performed for comparison. The fruit dropping time, number of fruits, fruiting rate, and seed setting rate of single fruits were determined.

\subsection{Seed Germination and Seedling Survival Experiment}

\subsubsection{Dynamic Changes in S. $\times$ hainanensis Seeds under Natural Conditions}

Three parental trees were randomly selected, and there were no $S . \times$ hainanensis trees within $50 \mathrm{~m}$ around the three mother trees. In order to calculate the number of fruits dropped, at the beginning of the fruit drop, every 5 days all the fruits dropped were collected and brought back to the laboratory for germination experiments until fruit dropping ceased.

One small quadrat of $1 \mathrm{~m} \times 1 \mathrm{~m}$ was set in four regions of $1 \mathrm{~m}, 3 \mathrm{~m}, 5 \mathrm{~m}$, and $10 \mathrm{~m}$ away from each parent tree. Thirty mature fruits covered with wire netting (mesh size was $50 \mathrm{~mm} \times 50 \mathrm{~mm}$ ) were naturally placed in each quadrat. A seed germination experiment was set up, not far from each quadrat. Eighty seeds were scattered on the ground, and the seeds were covered with a plastic mesh (mesh size was $1 \mathrm{~mm} \times 1 \mathrm{~mm}$ ). There were 3 replicates around a parental tree. The number of fruit predated by animals and seed germination rate at different distances from the parent trees were counted.

\subsubsection{The Relationship between S. $\times$ hainanensis Seed Germination and Environmental Factors}

Germination tests were performed indoors. Each test included 50 full seeds with three replicates. The seeds were first disinfected with $0.1 \%$ potassium permanganate solution for $5 \mathrm{~min}$, rinsed with distilled water, and then sown into $11 \mathrm{~cm}$ Petri dishes padded with filter paper. Distilled water (for light and temperature experiments) and saline (for salinity experiments) were added until the seeds were immersed in solution. Seed germination was observed daily after sowing and the liquid was changed 
once daily. The germinated seeds were transferred into another dish. After $5 \mathrm{~d}, 10$ strains were selected from each dish to measure the radicle length and perfectness ratio. Germination rate, germination potential, radicle length, and radicle perfectness ratio were calculated using a germination standard of a radicle length of $3 \mathrm{~mm}$ and an experimental time of $20 \mathrm{~d}$.

The light-dark cycles were set to 4/20,8/16, 12/12, 16/8, and 24-hour light/0 hours darkness. The temperature was set to $28^{\circ} \mathrm{C}$ during the day and $23{ }^{\circ} \mathrm{C}$ during the night. Relative air humidity $(75 \%)$ and light intensity (700 lx) were constant during treatment, and complete darkness was used as the control. All tests were divided into six treatment groups.

Seeds were sown in culture dishes and placed in an incubator set to different constant temperatures $\left(15,20,25,30,35,40\right.$, and $\left.45^{\circ} \mathrm{C}\right)$. The glass door was closed to allow the seeds to germinate under natural indoor light.

Ten groups with different salinities (0\%o, 2.5\%o, 5\%o, 7.5\%o, 10\%o, $12.5 \%$ o, 15\% , 20\%o, 25\%o, and $30 \%$ ) were prepared, and saline with the salinity of seawater (18.4\%o to $19.2 \%$ ) was used as the control. All tests were divided into 11 groups, and all germination experiments were conducted under indoor natural light in an incubator at a constant $35^{\circ} \mathrm{C}$. The seawater was replaced daily.

\subsection{Data Analysis Method}

Mean and standard error (SE) of three replicates were calculated. Data on all germination rates, germination viability, radicle lengths, and radicle perfectness ratio were analyzed for differences among different treatments by analysis of variance. If the difference was significant at $p<0.05$, a Duncan test was employed to determine the potential source of the difference. All statistical analyses were performed with SPSS, version 16.0 (SPSS Inc., Chicago, Illinois, U.S.A.). Statistical significance was defined as $p<0.05$.

\section{Results}

\subsection{Determination of the Reproductive System}

S. $\times$ hainanensis has a bell-shaped calyx tube. The top of the flower was about $4.5 \mathrm{~cm}$ to $5.5 \mathrm{~cm}$ from the base. The flower diameter was measured from the bell-shaped central part, which was approximately $2.4 \mathrm{~cm}$ to $3.2 \mathrm{~cm}$. Flowers with diameters greater than $6 \mathrm{~mm}$ were still scored 3 . In the field experiments, if the anther dehiscence of $S . \times$ hainanensis flowers presented no time interval from stigma receptivity, it was scored as 0 . If the stigma grew faster than stamens and kept ahead of stamens, it was scored as 1 . Thus, the OCI of $S . \times$ hainanensis was 4 , which indicates that the sexual reproductive system of $S . \times$ hainanensis is partially self-compatible, outcrossing, and needs pollinators.

Table 1 shows the $\mathrm{P} / \mathrm{O}$ ratio values of $S . \times$ hainanensis. According to Cruden, $\mathrm{P} / \mathrm{O}$ ratio values between 244.7 and 2588.0 indicate facultative outcrossing. Thus, the sexual reproduction system of $S$. $\times$ hainanensis is dominated by facultative outcrossing (Table 1 ).

Table 1. Pollen to ovule $(\mathrm{P} / \mathrm{O})$ ratio of Sonneratia $\times$ hainanensis.

\begin{tabular}{ccccc}
\hline $\begin{array}{c}\text { Items of } \\
\text { Observation }\end{array}$ & $\begin{array}{c}\text { Number of Pollen } \\
\text { in Each Simple } \\
\text { Flower (P) }\end{array}$ & $\begin{array}{c}\text { Number of Ovules } \\
\text { in Each Simple } \\
\text { Flower (O) }\end{array}$ & P/O Ratio & $\begin{array}{c}\text { Types of Breeding } \\
\text { System }\end{array}$ \\
\hline Results & $\approx 12500 \pm 2000$ & $34 \pm 10$ & 354 & Xenogamy \\
\hline
\end{tabular}

\subsection{Exploring Dysgenesis in $S . \times$ hainanensis}

\subsubsection{Pollen Germination Rate and Stigma Receptivity}

Under natural conditions, the pollen germination rate and stigma receptivity of single $S$. $\times$ hainanensis flowers is usually consistent with time (Figure 2). The pollen germination rate was highest $(100 \%$ or close to $100 \%)$ on the first and second day of flowering. The pollen germination rate declined 
greatly by the third day and was lowest (20\%) by the fifth day. Stigma receptivity peaked on the day of flowering, and $100 \%$ of the pollinated flowers bore fruits. On the fifth day of flowering, the entire style withered and stigma receptivity (5\%) was almost lost.

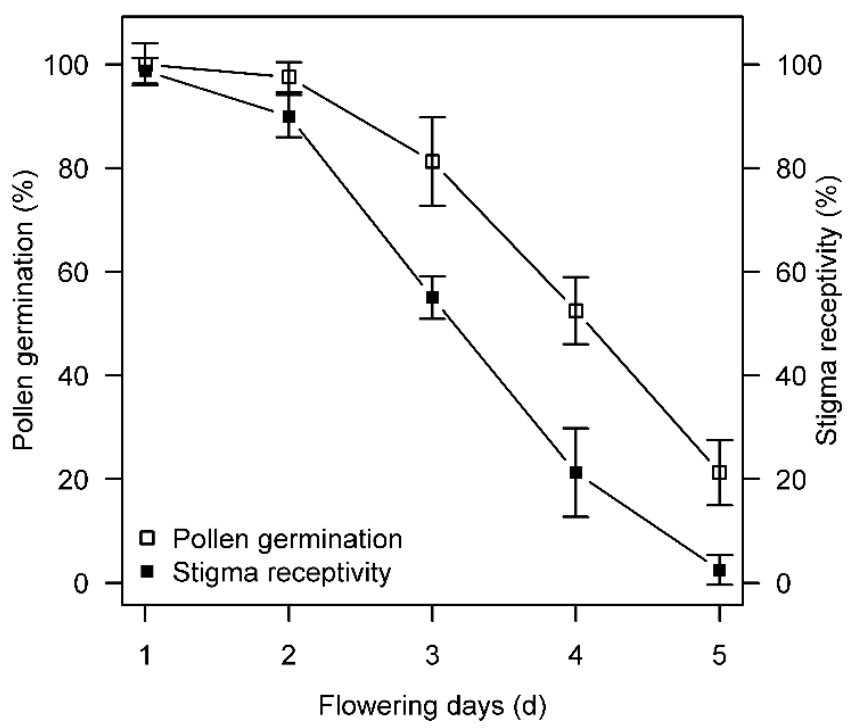

Figure 2. Variations in pollen germination rate and stigma receptivity with flower age in S. $\times$ hainanensis.

\subsubsection{Artificial Pollination Experiment}

After bagging with castration (apomixia), the $S . \times$ hainanensis ovaries grew slightly larger around the 10th day, and then stopped changing. After one month, the ovaries withered and dropped. The fruit setting rate was 0 (Table 2). Under natural conditions, the fruiting rate of $S . \times$ hainanensis was $45 \%$. The fruiting rate without bagging with castration was very low $(17.5 \%)$. The fruiting rate $(10 \%)$ under net isolation with castration was lower than that under natural pollination. However, under artificial pollination, the fruiting rate in all treatment conditions (42.5\% to $62.5 \%$ ) increased remarkably.

Table 2. Fruit setting rate and seed setting number under different pollination methods.

\begin{tabular}{cccccc}
\hline Pollination Method & $\begin{array}{c}\text { Number of } \\
\text { Flowers }\end{array}$ & $\begin{array}{c}\text { Fruit } \\
\text { Dropping } \\
\text { Time (d) }\end{array}$ & $\begin{array}{c}\text { Number } \\
\text { of Fruits }\end{array}$ & $\begin{array}{c}\text { Fruiting } \\
\text { Rate (\%) }\end{array}$ & $\begin{array}{c}\text { Seed Setting } \\
\text { Number in a } \\
\text { Single Flower }\end{array}$ \\
\hline Net isolation with castration & 40 & 7 & 4 & 10 & 16.25 \\
Bagging with castration & 40 & 0 & 0 & 0 & 0 \\
No bagging treatment & 40 & 7 & 7 & 17.5 & 19 \\
Natural pollination & 40 & 7 & 18 & 45 & 30.4 \\
Artificial self-pollination & 40 & 15 & 17 & 42.5 & 24.2 \\
Artificial geitonogamy & 40 & 15 & 20 & 50 & 34.6 \\
Artificial xenogamy & 40 & 18 & 25 & 62.5 & 56.2 \\
\hline
\end{tabular}

\subsection{Relationships among Seed Germination, Survival of Seedlings, and Environmental Factors}

\subsubsection{Seed Germination Rate at Different Fruit Dropping Times}

The artificial control experiment for the seed germination rate of dropped fruits at different times indicated that all indices significantly increase with increasing fruit dropping times (Table 3). At the fruit dropping time of $5-10 \mathrm{~d}$, the seed germination rate was 0 , and the seed germination rate was less than $10 \%$ at $20-25 \mathrm{~d}$. When the fruit dropping time was $30 \mathrm{~d}$, the number of fruit falling (84.67\%) and the seed germination rate $(46.55 \%)$ reached the maximum. When the fruit drop time was $35 \mathrm{~d}$, the fruit was no longer dropped. A chi square test showed that the seed germination rate was highly correlated 
with fruit dropping time $\left(\chi^{2}=63.29, p<0.01\right)$. This indicates that under natural conditions, the early dropping of $S . \times$ hainanensis fruits leads to the incapacity of immature seeds to germinate, which could result in source limitation of seed.

Table 3. Fruit dropping amount and seed germination rate of $S . \times$ hainanensis at different fruit dropping times.

\begin{tabular}{|c|c|c|c|c|c|c|c|}
\hline Dropping Time & $5 \mathrm{~d}$ & $10 \mathrm{~d}$ & $15 \mathrm{~d}$ & $20 \mathrm{~d}$ & $25 \mathrm{~d}$ & $30 \mathrm{~d}$ & $35 d$ \\
\hline Fruit dropping amount & $\begin{array}{c}14.67 \pm \\
4.51 \mathrm{f}\end{array}$ & $\begin{array}{c}25.67 \pm \\
4.04 \mathrm{e}\end{array}$ & $\begin{array}{c}39.33 \pm \\
9.24 \mathrm{~d}\end{array}$ & $\begin{array}{c}58.00 \pm \\
8.00 \mathrm{c}\end{array}$ & $\begin{array}{c}70.33 \pm \\
4.51 \mathrm{ab}\end{array}$ & $\begin{array}{c}84.67 \pm \\
6.43 a\end{array}$ & $0 \pm 0 \mathrm{~g}$ \\
\hline Seed germination rate $(\%)$ & $0 \pm 0 \mathrm{~d}$ & $0 \pm 0 \mathrm{~d}$ & $2 \pm 0 b c$ & $9 \pm 0 b$ & $43 \pm 3 a$ & $45 \pm 3 a$ & $0 \pm 0 \mathrm{~d}$ \\
\hline
\end{tabular}

Different letters indicate significant difference $(p<0.05)$.

\subsubsection{Dynamic Observation and Verification of Seeds under Natural Conditions}

It can be seen from Table 4 that under natural conditions, the fruit predation rate and seed germination rate at different distances are $100 \%$ and 0 . The seed destruction rate (by animals and disease) and seed remaining rate were about $82.5 \%$ and $17.5 \%$, respectively. Through field observations, it was found that crabs, squirrels, etc., were the main predators. In addition, the remaining seeds could not germinate. This indicates that the seed germination of $S . \times$ hainanensis under natural conditions is not only affected by animal predation, but also by habitat factors.

Table 4. Dynamic changes of fruit and seeds of $S . \times$ hainanensis under natural conditions.

\begin{tabular}{ccccc}
\hline Sampling Point & $\begin{array}{c}\text { Fruit Predation } \\
\text { Rate (\%) }\end{array}$ & $\begin{array}{c}\text { Seed Germination } \\
\text { Rate (\%) }\end{array}$ & $\begin{array}{c}\text { Seed Damage Rate } \\
\mathbf{( \% )}\end{array}$ & $\begin{array}{c}\text { Seed Remaining } \\
\text { Rate (\%) }\end{array}$ \\
\hline $1 \mathrm{~m}$ & 100 & 0 & $83 \pm 10$ & $17 \pm 10$ \\
$3 \mathrm{~m}$ & 100 & 0 & $85 \pm 0$ & $15 \pm 0$ \\
$5 \mathrm{~m}$ & 100 & 0 & $80 \pm 6$ & $20 \pm 6$ \\
$10 \mathrm{~m}$ & 100 & 0 & $82 \pm 13$ & $18 \pm 13$ \\
Average & 100 & 0 & $82.5 \pm 2.08$ & $17.5 \pm 2.08$ \\
\hline
\end{tabular}

\subsubsection{Effects of Light Cycle Duration on S. $\times$ hainanensis Seed Sprouting}

The seeds in the dark control group did not germinate. The germination rate, germination potential, radicle length, and radicle perfectness ratio were zero. Germination rate (Figure 3a), germination potential (Figure 3b), and radicle length (Figure 3c) demonstrated unimodal curves with increasing light cycle duration. Germination rate, germination potential, and radicle length differed under different light cycle durations (Figure 3$)$. The germination rate $(68.67 \%)$ and germination potential $(58.67 \%)$ peaked at $12 \mathrm{~h}$. The radicle length and radicle perfectness ratio did not statistically differ among different groups, except for the control group and the group at $4 \mathrm{~h}$ (Figure $3 \mathrm{~d}$ ). 

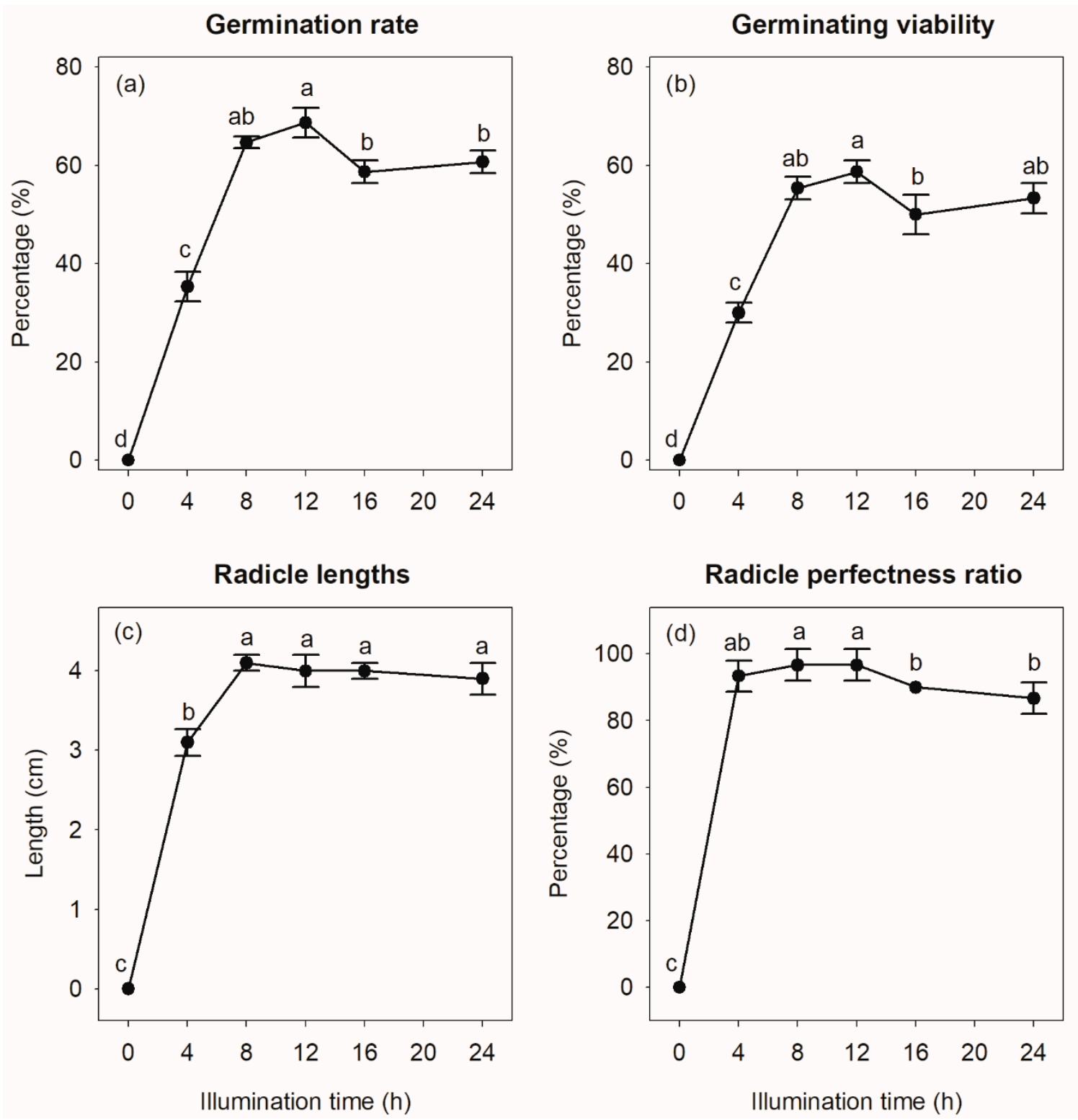

Figure 3. Effects of different illumination times on indicators. Different letters indicate significant difference $(p<0.05)$.

\subsubsection{Effect of Temperature on S. $\times$ hainanensis Sprouting}

The $S . \times$ hainanensis sprouting rate, germination potential, and radicle length exhibited remarkable differences under different temperatures (Figure 4). As the temperature increased, the germination rate, germination potential, and radicle length of all groups showed unimodal curve changes (Figure $4 a-c$ ). The germination rate and germination potential increased from $30^{\circ} \mathrm{C}$ to $35^{\circ} \mathrm{C}$. The germination rate $(90.67 \%)$ and the germination potential $(78.00 \%)$ peaked at $35^{\circ} \mathrm{C}$. The germination potential reached its minimum at $15{ }^{\circ} \mathrm{C}$ and the germination rate reached its minimum at $45^{\circ} \mathrm{C}$. As the temperature increased, the radicle length and the radicle perfectness ratio also presented unimodal curve changes (as shown in Figure $4 \mathrm{c}, \mathrm{d})$. The radicle length $(4.83 \mathrm{~cm})$ and the radicle perfectness ratio $(100 \%)$ peaked at $35^{\circ} \mathrm{C}$. 
Germination rate

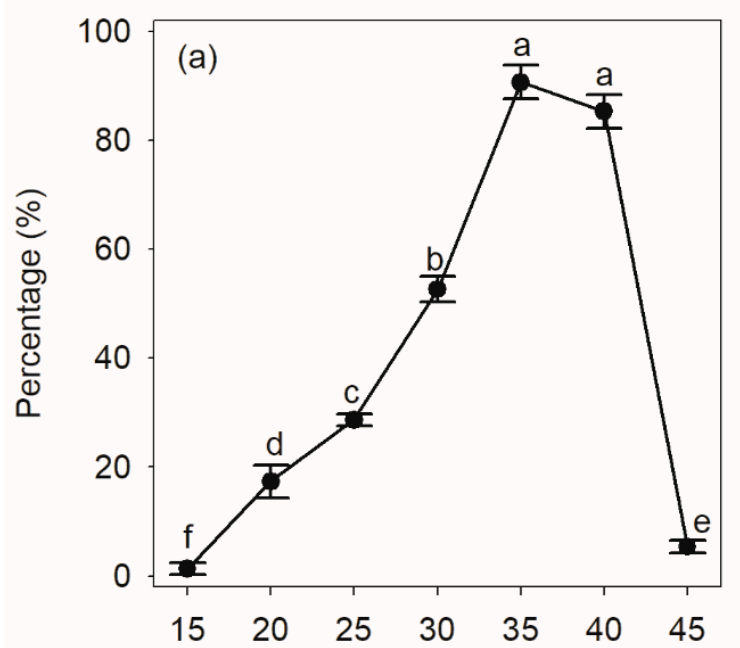

Radicle lengths

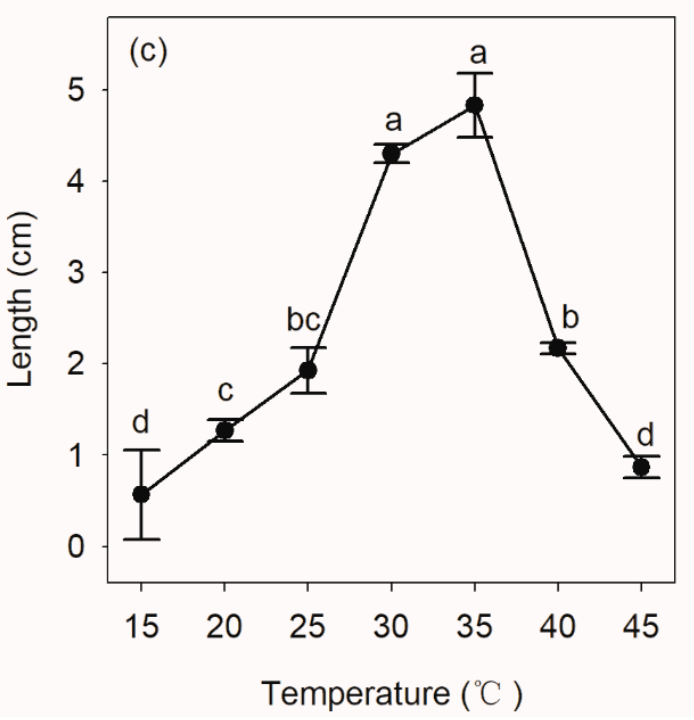

Germinating viability

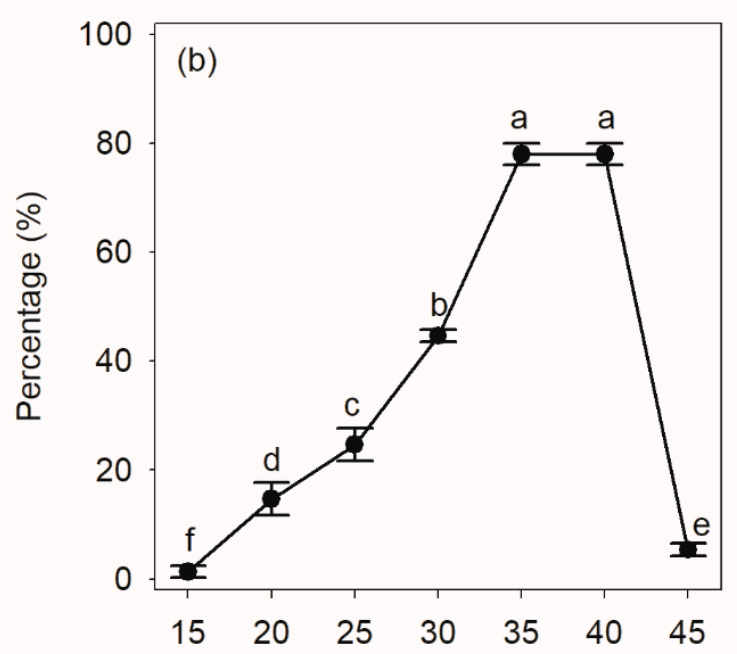

Radicle perfectness ratio

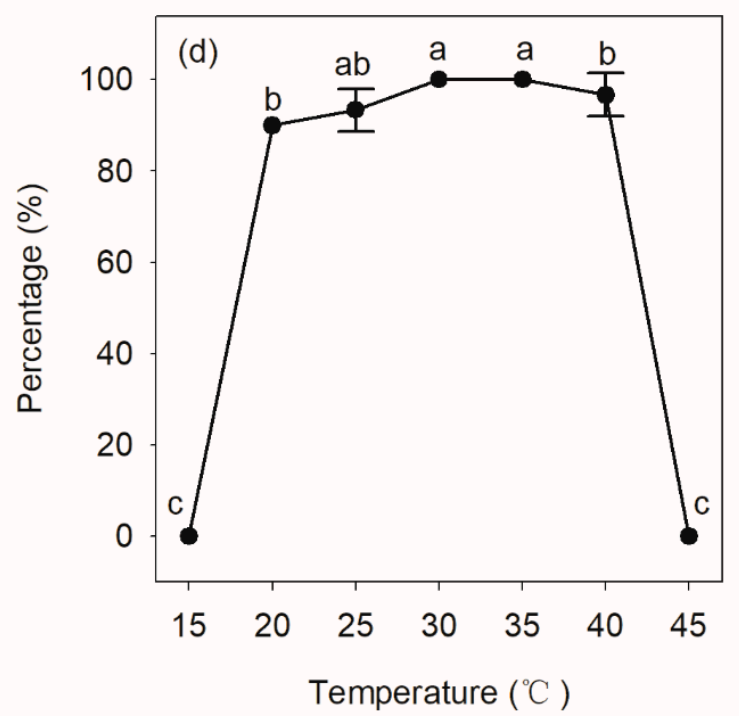

Figure 4. Effects of different temperatures on indicators. Different letters indicate significant difference $(p<0.05)$.

\subsubsection{Effect of Salinity on S. $\times$ hainanensis Seed Germination}

As salinity increased, the germination rate, germination potential, radicle length, and intact rate of each group significantly decreased (Figure 5$)$. The germination rate $(82.67 \%)$ and the germination potential $(75.33 \%)$ peaked at $0 \%$ o salinity (Figure $5 a, b)$. The difference was not obvious compared to the germination rate $(81.33 \%)$ and germination potential $(72.67 \%)$ at $2.5 \%$ o salinity. However, the radicle growth of the latter was more robust and the radicle perfectness ratio was ideal (100\%; Figure 5d); radicle length under low salinity $(<7.5 \%$ o) almost doubled under high salinity ( $>10 \%$ o) (Figure 5c). The appropriate germination salinity of $S . \times$ hainanensis varied from $0 \%$ o to $7 \%$. 

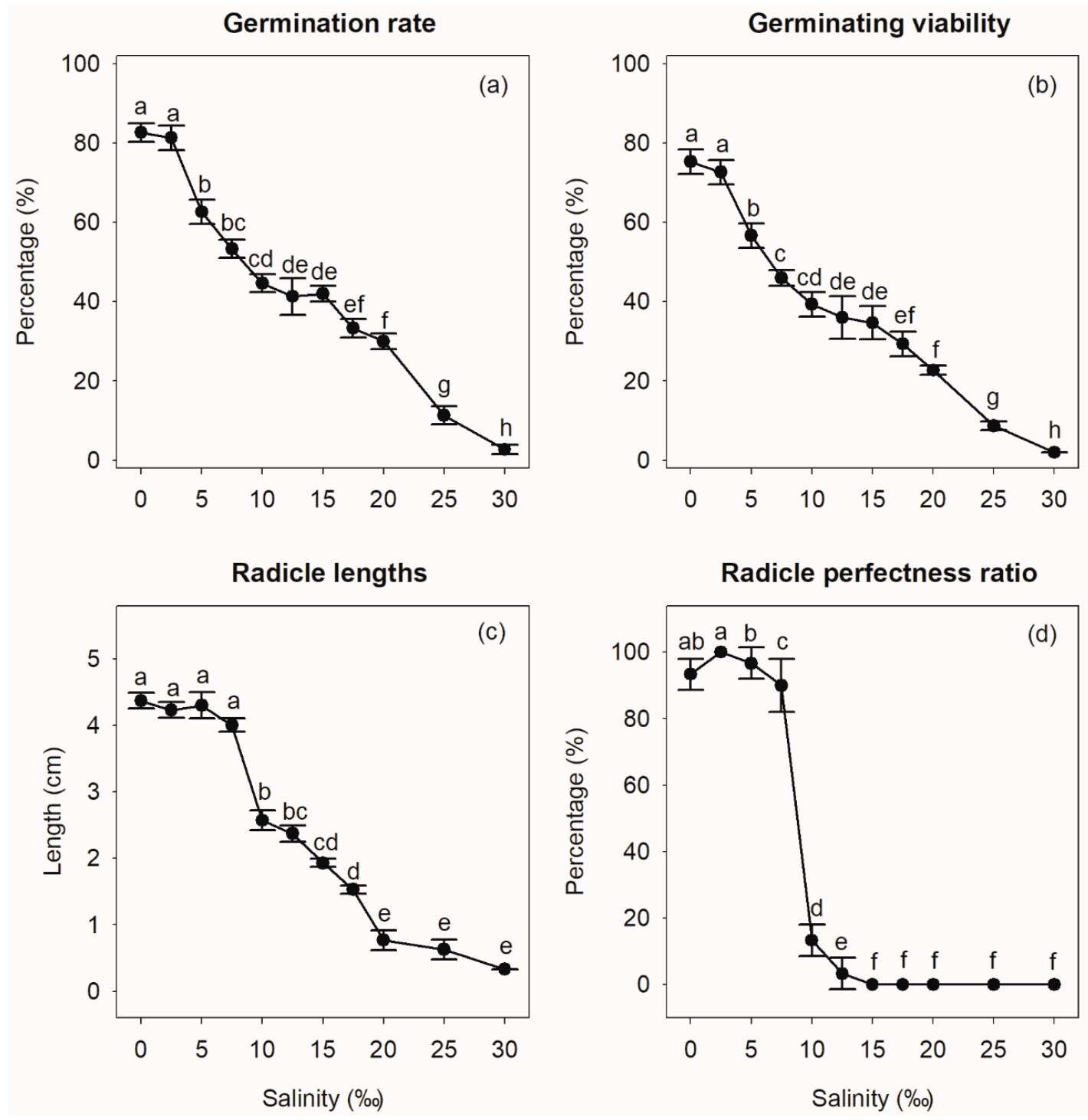

Figure 5. Effects of different salinities on indicators. Different letters indicate significant difference $(p<0.05)$.

\section{Discussion}

\subsection{Reproductive System of $S . \times$ hainanensis}

The understanding of the plant reproductive system is a prerequisite for understanding the life history of plants, and is also the basic background knowledge required for other related research [30]. Due to the different gender systems of plants, they often exhibit diverse types of reproductive systems [31]. Different gender systems have different effects on their hybridization rate, pollination mechanism, and breeding system [32].

According to the standards by Dafni, further experiments can verify that the sexual reproductive system of $S . \times$ hainanensis is partially self-compatible, outcrossing, and needs pollinators [28]. Based on the $\mathrm{P} / \mathrm{O}$ ratio by Cruden, its reproductive system is facultative outcrossing. Cross-pollination, especially xenogamy, has a high maturation rate [29]. The fruiting rate of artificial pollination is higher than the other pollination approaches. Thus, $S . \times$ hainanensis flowers have a mixed mating system. Selfing may mainly come from geitonogamous pollination. Moreover, the study by Tomlinson showed that geitonogamous plants have an outcross reproductive system [24]. The differences in these studies may be attributed to the narrowed population of $S . \times$ hainanensis, which led to a higher chance of selfing and inbreeding. During evolution, $S . \times$ hainanensis gradually changed from obligate outcrossing 
to facultative outcrossing with self-compatible tendencies. This reproductive system possibly evolved into a stable mixed mating system.

Research shows that small populations weaken the attraction of insects for pollination [33]. As a result, individual plants in small populations only acquire limited pollen with inferior quality compared to large populations, which leads to the pollen restriction on the reproductive success of small populations [33]. According to population genetics, small populations tend to undergo genetic drift, which reduces genetic diversity. This process is often accompanied by the accumulation of harmful mutations and it enhances inbreeding [34]. When populations shrink, the amount of pollen and its quality during pollination are greatly affected, which undermines reproduction [34]. According to research, only eight strains of $S$. $\times$ hainanensis are naturally distributed, with remarkable distances from each other. Under natural conditions, $S . \times$ hainanensis mainly conducts self-pollination. The artificial pollination experiment shows that artificially improving pollination notably improves the fruit setting rate of $S . \times$ hainanensis. The seed germination rate from the outcrossing population is much higher than from selfing. Therefore, pollen restriction and inbreeding depression can be attributed to the low seed germination rate of small populations, which is consistent with the finding of Li on Lumnitzera littorea (Jack) Voigt [35].

\subsection{Effects of Natural Environment on S. $\times$ hainanensis Seed Germination}

In the wild environment, in addition to abiotic factors (light, temperature, salinity), seed germination was also affected by biological factors (animals, diseases) [36]. The study of Taxus chinensis var. mairi has showed that only very small portions of the seed rain supplied the seed bank, and most of the falling seed did not replenish the soil seed bank due to predation, human disturbance, and environmental factors [37]. Seeds of Phoebe bournei were not only susceptible to soil pathogens, but to high predation beneath parent trees' canopy as well, which resulted in poor field seed germination [38].

In this experiment, the fruit drop of $S . \times$ hainanensis was serious during fruiting stages, and only the seeds of mature stage had higher germination rate (about $40 \%$ ), and the seed germination rate in other periods was very low (less than $10 \%$ ), so most of the fruits were wasted. Because the fruit of $S . \times$ hainanensis was sweet, it was welcomed by animals such as squirrels and Fiddler crabs. Most of the seeds were destroyed and could not be germinated. Therefore, seed predation by animals was also one of the reasons that the seed germination of $S . \times$ hainanensis was limited.

\subsection{Effects of Simulated Environmental Factors on S. $\times$ hainanensis Seed Germination}

Seed germination is the weakest phase for plants to resist environmental stress. Furthermore, factors that adversely affect seed germination directly influence the generation and supplementation of new individual plants into the population, as well as its stability [39]. In this research, the major obstacles to the regeneration of $S$. $\times$ hainanensis populations were closely related to seed germination and indispensable environmental factors that influence germination.

\subsubsection{Effect of Light on $S . \times$ hainanensis Seed Germination}

Light is indispensable for the seed germination of certain plants and different plants have different light requirements for seed germination [40]. Studies have shown that the seeds of the endangered plant, Garcinia paucinervis Chun \& F.C. How, can germinate in the presence or absence of light, indicating that light is not a necessary condition for its germination [41]. The seed of Lumnitzera littorea is a light-requiring seed [42]. Under darkness and constant temperature, the newly collected $S . \times$ hainanensis seeds did not completely germinate, and increased light promoted seed germination and radicle growth. Exposing the seeds to light for $12 \mathrm{~h}$ per day was optimal for germination. After the spreading of seeds, the weak air and water permeability of sludge under the forest results in insufficient light acquisition. Thus, most seeds only receive insufficient light, which causes an obvious decline in sprouting rate. Seedlings under the forests are scarce. Actual investigation reveals no $S . \times$ hainanensis 
seedling under the forest. Hence, the insufficient light in forests limits $S . \times$ hainanensis seed germination, which is consistent with the finding of Liao on S. caseolaris [43].

\subsubsection{Effect of Temperature on S. $\times$ hainanensis Seed Germination}

Temperature is one of the key factors during seed germination. However, the response of different endangered plant seeds to temperature is also different [44]. The endangered plant Cercidiphyllum japonicum Siebold \& Zuccarini has a low seed germination rate below $5{ }^{\circ} \mathrm{C}$, and there is no significant difference between $10{ }^{\circ} \mathrm{C}$ and $30^{\circ} \mathrm{C}$ [40]. The seed germination of most endangered plants, such as Dracaena cambodiana Pierre ex Gagnepain, Sinia rhodoleuca (Diels) M.C.E. Amaral and Lumnitzera littorea, are very sensitive to temperature, and $25^{\circ} \mathrm{C}$ is optimal. At the same time, seeds cannot germination when the temperature is below $15^{\circ} \mathrm{C}$, and if it is higher than $30^{\circ} \mathrm{C}$ [45-47]. Under laboratory conditions, the suitable temperature for $\mathrm{S}$. $\times$ hainanensis seed germination was between $30^{\circ} \mathrm{C}$ and $40^{\circ} \mathrm{C}$, with an optimum temperature of $35^{\circ} \mathrm{C}$. This condition indicates that $S . \times$ hainanensis seeds are sensitive to low temperatures, but are able to resist temperature changes within a small range. In 2008, because of extreme cold in southern China, all seedlings of $S . \times$ hainanensis were dead in the mangrove forest nature protection area of Dongzhaigang [48]. Therefore, temperature is also one of the factors limiting the seed germination of $S . \times$ hainanensis.

\subsubsection{Effect of Salinity on S. $\times$ hainanensis Seed Germination}

The optimum salinity for $S . \times$ hainanensis seed was between $0 \%$ ond $7.5 \%$. Within this range, the germination potential, germination rate, radicle length, and radicle perfectness ratio, which reflect the sprouting ability, are better than those under other salinities. Further increases in salinity caused a drop in germination potential, germination rate, radicle length, and radicle perfectness ratio, which demonstrates that low salinity is conducive to $S$. $\times$ hainanensis seed germination, whereas high salinity inhibits germination. This result is consistent with findings that most halophytic plants have higher germination rates at low salinities [49-51].

Generally, seed germination at low salinity only slightly differs from that at $0 \%$ salinity. Increasing salinity gradually inhibits germination, but the seeds of most plants regain their vigor after being transferred into freshwater, which increases their accumulated germination rate [52]. For example, placing seeds that cannot germinate under high salinity into fresh water partially restores their germination rate, which shows that high salinity triggers dormancy in $S . \times$ hainanensis seeds. Exposing the seeds to optimal conditions allows them to germinate. This may be an important adaptation mechanism for $S . \times$ hainanensis in saline environments. Studies in China on the seed germination and seedling growth of other mangrove trees such as $S$. apetala under saline stress revealed that seed germination is better under low salinity than under high salinity [53]. This observation is partially consistent with the findings in this experiment. The $S . \times$ hainanensis seeds exhibited the highest germination index under $0 \%$ salinity and the low salinity value $(2.5 \%$ o). However, radicle growth was more robust and the radicle perfectness ratio was higher under low salinity. This observation implies that $S . \times$ hainanensis seed germination requires stimulation under a certain salinity to allow the radicle to grow more robustly, more adaptable to the saline environment, and to improve the survival rate of seedlings. In addition, the seawater salinity control demonstrates that salinity limits the seed germination of $S . \times$ hainanensis.

\section{Conclusions}

Ecological analysis of the reproductive system, seeds, and seedlings indicated that the following factors limit the regeneration of $S . \times$ hainanensis: (1) Pollen limitation and inbreeding recession caused by the extremely small population of $S . \times$ hainanensis. (2) Seeds near parent trees are susceptible not only to high fruit drop rate, but to high predation beneath parent trees' canopy as well. (3) Seed germination has weak adaptability to light, temperature, and salinity. 
To protect $S . \times$ hainanensis, we recommend implementing artificial xenogamy during the flowering stage to improve pollination efficiency, the fruit setting rate, and the fruiting, as well as building a small simulation greenhouse and collecting seeds in time. The populations can be expanded through indoor seedling breeding and domestication to factors such as salinity.

Author Contributions: Conceptualization, M.Z. and X.Y.; data curation, M.Z. and X.L.; funding acquisition, D.L.; investigation, M.Z. and X.L.; methodology, M.Z.; project administration, X.Y.; resources, W.L.; writing-original draft, M.Z.; writing - review and editing, M.Z. and X.Y.

Funding: This work was financially supported by the China National key R \& D Program during the 13th Five-Year Plan Period (2016YFC0503100).

Acknowledgments: We thank LetPub (https://www.letpub.com.cn/) for editing this manuscript.

Conflicts of Interest: The authors declare no conflict of interest.

\section{References}

1. Arroyo, J.; Thompson, J.D. Plant reproductive ecology and evolution in a changing Mediterranean climate. Plant Boil. 2018, 20, 3-7. [CrossRef]

2. Sheng, M.Y.; Shen, C.Z.; Chen, X.; Tian, X.J. Resource status and protection countermeasures of endangered wild plants in China. Chin. J. Nat. 2011, 33, 455-467.

3. Liu, K.Q.; Deng, H.P. Floral biology and breeding system of endangered plant Scutellaria tsinyunensis endemic to Chongqing, China. Bull. Bot. Res. 2011, 31, 403-407.

4. Sigrist, M.R.; Sazima, M. Phenology, reproductive biology and diversity of buzzing bees of sympatric Dichorisandra species (Commelinaceae): breeding system and performance of pollinators. Plant Syst. Evol. 2014, 301, 1005-1015. [CrossRef]

5. Tsuji, K.; Ohgushi, T. Florivory indirectly decreases the plant reproductive output through changes in pollinator attraction. Ecol. Evol. 2018, 8, 2993-3001. [CrossRef]

6. Waelti, M.O.; Muhlemann, J.K.; Widmer, A.; Schiestl, F.P. Floral odour and reproductive isolation in two species of Silene. J. Revolut. Biol. 2008, 21, 111-121. [CrossRef]

7. Gross, C.L.; Bartier, F.V.; Mulligan, D.R. Floral structure, breeding system and fruit-set in the threatened sub-shrub Tetratheca juncea Smith (Tremandraceae). Ann. Bot. 2003, 92, 771-777. [CrossRef]

8. Hamston, T.J.; Wilson, R.J.; De Vere, N.; Rich, T.C.G.; Stevens, J.R.; Cresswell, J.E. Breeding system and spatial isolation from congeners strongly constrain seed set in an insect-pollinated apomictic tree: Sorbus subcuneata (Rosaceae). Sci. Rep. 2017, 7, 45122. [CrossRef]

9. Sawyer, N.W. Reproductive Ecology of Trillium recurvatum (Trilliaceae) in Wisconsin. Am. Midl. Nat. 2010, 163, 146-160. [CrossRef]

10. Opedal, Ø.H.; Armbruster, W.S.; Pélabon, C. Inbreeding effects in a mixed-mating vine: effects of mating history, pollen competition and stress on the cost of inbreeding. AoB PLANTS 2015, 7, 133. [CrossRef]

11. Takebayashi, N.; Morrell, P.L. Is self-fertilization an evolutionary dead end? Revisiting an old hypothesis with genetic theories and a macro-evolutionary approach. Am. J. Bot. 2001, 88, 1143-1150. [CrossRef] [PubMed]

12. Bebawi, F.F.; Campbell, S.D.; Mayer, R.J. Seed ecology of Captain Cook tree [Cascabela thevetia (L.) Lippold] germination and longevity. Rangel. J. 2017, 39, 307. [CrossRef]

13. Oakley, C.G.; Ågren, J.; Schemske, D.W. Heterosis and outbreeding depression in crosses between natural populations of Arabidopsis thaliana. Heredity 2015, 115, 73-82. [CrossRef] [PubMed]

14. Prill, N.; Bullock, J.M.; Van Dam, N.M.; Leimu, R. Loss of heterosis and family-dependent inbreeding depression in plant performance and resistance against multiple herbivores under drought stress. J. Ecol. 2014, 102, 1497-1505. [CrossRef]

15. Jiménez-Alfaro, B.; Silveira, F.A.; Fidelis, A.; Poschlod, P.; Commander, L.E. Seed germination traits can contribute better to plant community ecology. J. Veg. Sci. 2016, 27, 637-645. [CrossRef]

16. Phartyal, S.S.; Rosbakh, S.; Poschlod, P. Seed germination ecology in Trapa natans L., a widely distributed freshwater macrophyte. Aquat. Bot. 2018, 147, 18-23. [CrossRef]

17. Zhang, S.X. A preliminary study on cutting propagation techniques for old plants of Cinnamomum micranthum. J. Fujian Sci. Tech. 2000, 27, 69-71. 
18. Xie, Z.Q.; Chen, W.L. The endangered causes and protection measures of Cathaya argyrophylla, an endemic to China. Acta Phytoecol. Sin. 2003, 27, 661-666.

19. Gao, Y.Z. Sonneratiaceae: The Flora of China; Science Press: Beijing, China, 1983; pp. 114-116.

20. Lin, P.; Lu, C.Y. Mangrove community in Hainan Island. J. Xiamen Univ. 1985, 24, 1117-1119.

21. Li, H.S.; Chen, G.Z. Biological characteristics and protection of Chinese endemic plant S. $\times$ hainanensis. J. Guangdong Educ. Inst. 2003, 23, 48-51.

22. Zhang, Z.; Guo, Y.; He, J.-S.; Tang, Z. Conservation status of wild plant species with extremely small populations in China. Biodivers. Sci. 2018, 26, 572-577. [CrossRef]

23. Duke, N.C. A mangrove hybrid, Sonneratia $\times$ gulngai (Sonneratiaceae) from north-eastern Australia. Austrobaileya 1984, 2, 103-105.

24. Tomlinson, P.B. The botany of Mangroves; Cambridge University Press: Cambridge, UK, 1986.

25. Zhang, Y.L.; Wang, K.F.; Li, Z. Study on pollen morphology(Sonneratiaceae) in China and Its paleoecological significance. Mar. Geol. Quat. Geol. 1997, 17, 2993-3001.

26. Renchao, Z. Natural Hybridization and Speciation in Sonneratia. Ph.D. Thesis, Zhongshan University, Guangzhou, China, 2006.

27. Li, H.S.; Chen, G.Z.; Si, S.H. ISSR study on genetic diversity of Hainan Sanghai. Acta Sci. Nat. Univ. Sunyatseni 2004, 43, 68-70.

28. Dafni, A. Pollination Ecology; Oxford University Press: New York, NY, USA, 1992.

29. Cruden, R.W. Pollen-ovule ratios: A conservative indicator of reproductive systems in flowering plants. Evolution 1977, 31, 32-46. [CrossRef] [PubMed]

30. Holsinger, K.E. Pollination biology and the evolution of mating systems in flowering plants. Evol. Biol. 1996, 29, 107-149.

31. Morgan, J.W. Effects of population size on seed production and germinability in an endangered, fragmented grassland plant. Conserv. Boil. 1999, 13, 266-273. [CrossRef]

32. Bie, P.F.; Tang, T.; Hu, J.Y.; Jiang, W. Flowering phenology and breeding system of an endangered and rare species Urophysa rockii(Ranunculaceae). Acta Ecol. Sin. 2018, 38, 3899-3908.

33. Lande, R. Risk of population extinction from fixation of new deleterious mutations. Evolution 1995, 48, 1460-1469. [CrossRef]

34. Kéry, M.; Matthies, D.; Spillmann, H.H. Reduced fecundity and offspring performance in small populations of the declining grassland plants Primula veris and Gentiana lutea. J. Ecol. 2000, 88, 17-30. [CrossRef]

35. Zhang, Y.; Li, Y.H.; Zhang, X.N.; Yang, Y. Flower phenology and breeding system of endangered mangrove Lumnitzera littorea (Jack.) Voigt. Chin. J. Appl. Env. Biol. 2017, 23, 0077-0081.

36. Zhang, J.H.; Liu, B.W. Patterns of seed predation and removal of Mongolian oak by rodents. Acta Ecol. Sin. 2014, 34, 1201-1211.

37. Yue, H.J.; Tong, C.; Zhu, J.M.; Huang, J.F. Seed rain and soil seed bank of endangered Taxus chinensis var mairei in Fujian, China. Acta Ecol. Sin. 2010, 30, 4389-4400.

38. Wu, D.R.; Wang, B.S. Seed and seedl ing ecology of the endangered Phoebe bournei (Lauraceae). Acta Ecol. Sin. 1997, 11, 1752-1757.

39. Manfred, J.; Lesley, P.; Birgitte, S. Habitat specificity, seed germination and experimental translocation of the endangered herb Brachycome muelleri (Asteraceae). Biol. Conserv. 2004, 116, 251-267.

40. Finch-Savage, W.E.; Leubner-Metzger, G. Seed dormancy and the control of germination. New Phytol. 2006, 171, 501-523. [CrossRef]

41. Zhang, J.J.; Chai, S.F.; Wei, X.; Lv, S.H.; Wu, S.H. Germination characteristics of the seed of a Rare and endangered plant, Garcinia paucinervis Australia. Sci. Silvae Sin. 2018, 54, 175-178.

42. Yang, Y.; Zhong, C.R.; Li, Y.H.; Zhang, Y. The morphological structure and germination characters of seed of endangered Mangrove Lumnitzera littorea (Jack.) Voigt. Mol. Plant Breed. 2016, 14, 2851-2858.

43. Liao, B.W.; Zheng, D.Z.; Zheng, S.F.; Li, Y. Seed germination conditions of Sonneratia caseolaris of mangrove. J. Cent. South For. Univ. 1997, 17, 25-27.

44. Xu, X.L. Effects of Cold Storage and Temperature on Seed Germination Characteristics of Two Common Plants in Alpine Meadow. Ph.D. Thesis, Lanzhou University, Lanzhou, China, 2007.

45. Li, W.L.; Zhang, X.P.; Hao, C.Y.; Zhang, H.; Holsinger, K.E. Characteristics of seed germination of the rare plant Cercidiphyllum japonicum. Acta Ecol. Sin. 2008, 28, 107-149. 
46. Chai, S.F.; Jiang, J.S.; Wei, X.; Wang, M.L.; Li, L.; Qi, X.X. Seed germination characteristics of endangered plant Sinia rhodoleuca. Chin. J. Ecol. 2010, 29, 233-237.

47. Zheng, D.J.; Wu, Y.J.; Yun, Y.; Jiang, D.Q.; Chen, X.; Zhang, Z.L. Seed germination and its environment adaptability of endangered tree Dracaena cambodiana. J. Trop. Subtrop. Bot. 2016, 24, 71-79.

48. Chen, L.Z.; Wang, W.Q.; Zhang, Y.H.; Huang, L.; Zhao, C.L.; Yang, S.C. Damage to mangroves from extreme cold in early 2008 in sourthern China. Chin. J. Plant Ecol. 2010, 34, 186-194.

49. You, H.-M. Adaptability of mangrove Kandelia obovata seedlings to salinity-waterlogging. Ying yong sheng tai $x$ ue bao = J. Appl. Ecol. 2015, 26, 675-680.

50. Tang, M.; Li, K.; Xiang, H.Y.; Dong, X.; Jin, H.X.; Wang, Y.; Yang, H.J.; Zhang, Z.X. Research on ecological, physiological and morphological adaptability of two mangrove species to salt stress. Ecol. Sci. 2014, 33, 513-519.

51. Zhang, Y.; Ye, Y.; Lu, C.Y. Seed germination and seedling growth of mangrove Excoecaria agallocha under different salinities. J. Xiamen Univ. 2010, 49, 145-148.

52. Khan, M.A.; Gul, B.; Weber, D.J. Germination responses to Salicornia rubra to temperature and salinity. J. Arid Env. 2000, 45, 207-214. [CrossRef]

53. Li, Y.; Zheng, D.Z.; Liao, B.W.; Zheng, S.F.; Song, X.Y. Effect of salinity and temperature on seed germination of mangrove Sonneratia apetala Buch. Ham. For. Res. 1997, 10, 137-142.

(C) 2019 by the authors. Licensee MDPI, Basel, Switzerland. This article is an open access article distributed under the terms and conditions of the Creative Commons Attribution (CC BY) license (http://creativecommons.org/licenses/by/4.0/). 